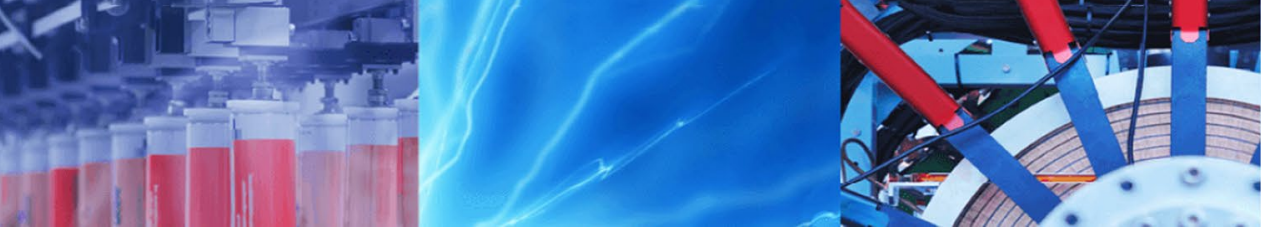

Research Article

\title{
Investigating the performance of GFRP/wood-based honeycomb sandwich panels for sustainable prefab building construction
}

\author{
Muzamil Hussain ${ }^{1} \cdot$ Naseem Abbas $^{2}$ (D) $\cdot$ Nida Zahra $^{3} \cdot$ Uzair Sajjad $^{4} \cdot$ Muhammad Bilal Awan $^{5}$
}

(c) Springer Nature Switzerland AG 2019

\begin{abstract}
The static failure behavior of innovative wood-based sandwich panels with wood-based core and face sheets made of glass fiber reinforced polymer was investigated. The sandwich panels were subjected to three-point bending and compression tests to determine their strengths and their failure mechanisms. The honeycomb core of medium density fiberboard (MDF) was manufactured to reduce the weight of the whole panel as well as the consumption of wood elements. The hollow portions of the honeycomb core were filled with wheat straw to increase the heat resistance of the whole structure by maintaining a lightweight. The tests showed that the mechanical characteristics of solid MDF structures were high as compared to MDF honeycomb panels. But, MDF honeycomb structures were superior because of their capability to sustain against the load after the failure. Load absorption capabilities and strength of honeycomb sandwich panels filled with wheat straw were little improved. The major fracture modes were transverse shear, longitudinal shear, and delamination. The delamination at core and facing interface was the significant problem which can effectively be reduced by using inserts into the core above face sheets.
\end{abstract}

Keywords Building construction · Honeycomb sandwich panels · Bending load · Compression load · Static failure behavior

\section{Introduction}

A sandwich structure is formed by attaching two thin and stiff face sheets to a lightweight, thick core [1-3]. Their particular properties such as high bending stiffness per unit weight, high strength per unit weight and high corrosion resistance are important benefits of these structures. These properties make them suitable for use in different sectors such as aeronautics, aerospace, marine, automobiles, railways, and packaging [4]. Sandwich structures have been also effectively used in civil infrastructures due to the high stiffness/high strength per unit weight and high corrosion resistance $[5,6]$.
A new era of wood building construction is at the beginning to minimize the diverse impact of buildings on the environment [7]. However, still, the utilization of wood as a building material is very low due to the relatively low load carrying ability than concrete [8]. Furthermore, the wood member decays with the passage of time due to the aggressive ecological conditions. Fiber reinforced polymers (FRP) composites have been commonly used as structural and strengthening members in the military, chemical, marine and civil infrastructures due to the excellent properties such as light-weight, high strength and stiffness, good damage tolerance and fatigue performance, corrosion resistance, design flexibility and non-magnetic behavior $[9,10]$ Therefore enhancements on durability and

$\triangle$ Naseem Abbas, naseem@cau.ac.kr| ${ }^{1}$ Mechanical Engineering Department, NFC Institute of Engineering and Technology, Multan, Pakistan. ${ }^{2}$ School of Mechanical Engineering, Chung-Ang University, Seoul 06974, Republic of Korea. ${ }^{3}$ Department of Physics, Government College University, Faisalabad, Pakistan. ${ }^{4}$ Mechanical Engineering Department, National Chiao Tung University, Hsinchu, Taiwan. ${ }^{5}$ Department of Mechanical Engineering, University of Central Punjab, Lahore, Pakistan. 
strength of concerned wood material by FRP can make the timber suitable for building construction.

Osei-Antwi et al. [11] investigated the span limits of GFRP-balsa sandwich panels. The sandwich panels were used directly as a slab of a bridge or as the deck of a hybrid sandwich steel girder bridge. Furthermore, the potential to replace concrete structures with sandwich panels was also evaluated. The steel plate inserts into balsa core above the steel girders were required to replace a concrete slab. Farkas et al. [12] developed the five-layer FRP sandwich beam to minimize the deflection and to enhance the stiffness. The optimization approach was used to reduce the design cost of the sandwich beam. A bridge of hybrid FRP/ concrete sandwich structure was constructed for weight minimization. Chen et al. [13] performed an experimental investigation to assess the performance of a hybrid $\mathrm{FRP} /$ concrete bridge. The full-scale laboratory specimen was subjected to static loading. After testing the original hybrid bridge design was optimized in term of material quantity and cost. Ziehl et al. [14] designed a hybrid fiber reinforced polymer/reinforced concrete bridge and constructed in Texas. For each live load evaluation strain and acoustic emission data was gathered and evaluated over a period of 2 years. Measurements indicated no sign of significant degradation in stiffness and damage.

Adhesive attachment of FRP to wood has been considered the common practice to achieve rehabilitation and reinforcement for enhancement in mechanical characteristics. There exists a considerable concern about the durable performance of the FRP/wood sandwich composite under the moisture effect. Zhou et al. [15] adopted the atomistic and experimental approaches for the investigation of moisture effect on entire FRP/wood sandwich structure. The absorption of water molecules at FRP/wood interface was found crucial and reduced adhesion energy and mechanical behavior at different humidity level.

Jiang et al. [16] introduced the non-traditional approach to manufacture sandwich structures of natural agricultural fibers. All materials were naturally derived including natural fiber (jute, cellulose, and hemp) as a face sheet, mycelium bound plants waste as a core and bio-resin as a matrix. The dried sandwich structures were subjected to flexural tests under three-point bending load to investigate the strength and stiffness of structures. The optimum performance in term of facing material and processing condition was determined. Matalkah et al. [17] also utilized locally available indigenous materials to develop sandwich structures for building construction. The chicken mesh of galvanized steel wire and jute were used for skins and aerated concrete (lime-gypsum) was selected for the core. These reinforcement systems were characterized through the performance of tension tests and compression tests respectively. Several experiments were performed to determine the required length of reinforcement and bond strength in the matrix. Flexural results of the whole sandwich structure indicated that the concrete core plays a significant role in the performance of the sandwich panel.

The selection and design of light-weight core is an important consideration for the development of sandwich structures. Honeycomb structures are most commonly used in sandwich composites as well as in many other industrial products because of high energy absorbing capability, high strength/stiffness, and strength/ weight ratios [18-20]. Honeycombs act in a different way under dynamic load in terms of failure modes and carry high fatigue life [21-23]. Engineered wood elements can be developed in honeycomb structures to reduce the consumption of wood products with maintaining the structural capacity. Hence, the objective of this work is to create cheap, sustainable and efficient material for prefab building construction. The wood-based sandwich panels with wood-based core and face sheets were developed. The wood-based honeycomb core was manufactured to reduce the weight of the whole structure as well as the consumption of wood elements. The hollow portions of honeycomb were filled with wheat straw in order to increase the heat resistance of the whole structure. The results were compared with the sandwich structure of solid wood core elements of same wood products as selected for honeycomb structures and with sandwich structures of a plywood core.

\subsection{Preparation of specimens}

In this study, sandwich structures with wood-based core and GFRP face sheets were manufactured. Different woodbased core materials were used in order to compare their properties. The dimensions of each sandwich panel were $200 \times 75 \times 25 \mathrm{~mm}$ based on requirements of the ASTM standard C393 standard [16]. The loading and geometrical configurations are shown in Fig. 1. Due to ease in machining process medium density fiberboard (MDF) was selected for hexagonal honeycomb core. In the first type of wood-based sandwich panels' hollow MDF honeycomb core was used, while in second type hollow areas of MDF honeycomb core were filled with wheat straw. Instead of honeycomb design, solid MDF core and plywood were also used for core materials. Locally available white glue was used as a resin for bonding core and facing with each other. To predict the mechanical properties of the core element bending test was performed according to the ASTM standard C393/C393 M, while compression test was performed according to the ASTM standard C365/365 M. The tensile properties of GFRP were predicted according to ASTM standard D-638. The materials properties are given in Table 1. 
Fig. 1 Schematic of loading and geometrical configurations a Mid span distance, $\mathbf{b}$ core and facing thickness

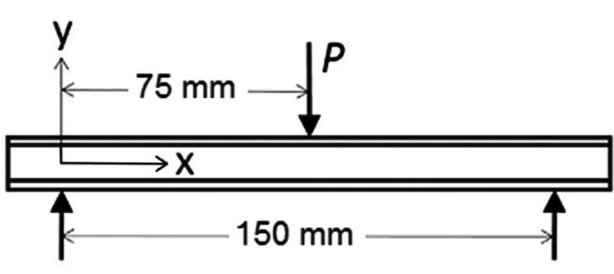

a

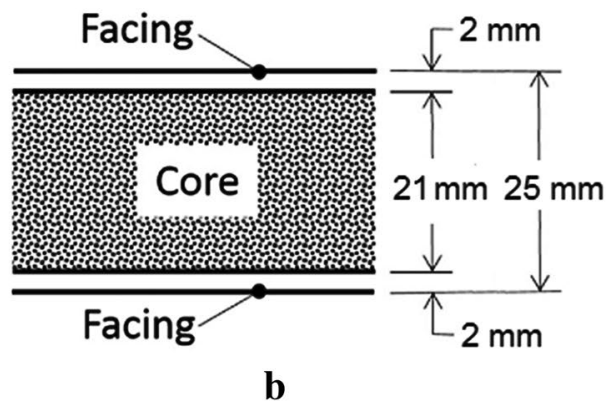

Table 1 Mechanical properties of core and facing materials

\begin{tabular}{llll}
\hline Parameter & $\begin{array}{l}\text { Facing material } \\
\text { Glass fiber rein- } \\
\text { forced polyester } \\
\text { (GFRP) }\end{array}$ & \multicolumn{2}{l}{ Core materials } \\
\cline { 3 - 4 } & $2140 \mathrm{~kg} / \mathrm{m}^{3}$ & $651 \mathrm{~kg} / \mathrm{m}^{3}$ & $733 \mathrm{~kg} / \mathrm{m}^{3}$ \\
\hline Density & 0.13 & 0.27 & 0.29 \\
Poisson ratio & $2415 \mathrm{MPa}$ & - & - \\
Tensile strength & - & $13.54 \mathrm{MPa}$ & $19.6 \mathrm{MPa}$ \\
Compressive Strength & - & $28.4 \mathrm{MPa}$ & $56.4 \mathrm{MPa}$ \\
Bending Strength & - & $1378 \mathrm{MPa}$ & $2582 \mathrm{MPa}$ \\
Modulus of Elasticity & $51.7 \mathrm{GPa}$ & $34.4 \mathrm{MPa}$ & $46.6 \mathrm{MPa}$ \\
Compressive Modulus & - & &
\end{tabular}

The resin was dispersed onto the core surface and GFRP sheet was placed on it. The mechanical pressure was applied on laminate during curing. All the samples were manufactured with the same method.

\subsection{Experimental setup}

The universal testing machine (UTM) was used for three points bending and compression tests. Three specimens of each type were loaded identically. The load span was set to $150 \mathrm{~mm}$ according to the ASTM standard C393/C393 M. All the tests were performed on $10 \mathrm{~mm} / \mathrm{min}$ loading rate. The core members including MDF honeycomb and solid MDF are shown in Fig. 2a, b respectively. The specimens under three-point bending and compression load are shown in Fig. 3. The load-deflection behavior of all samples was recorded until failure. Core shear ultimate stress $\left(F_{s}^{u l t}\right)$, maximum facing stress $\left(\sigma_{f}\right)$, panel stiffness $\left(\frac{\Delta P}{\Delta y}\right)$ and maximum bending stress of sandwich panel $\left(\sigma_{b}\right)$ are calculated using following formulas from Refs. $[16,4]$.

$F_{s}^{\text {ult }}=\frac{P_{\max }}{(d+c) b}$

$\sigma_{f}=\frac{P_{\max } \cdot S}{2 t(d+c) b}$
Fig. 2 Core panels a MDF honeycomb, b solid MDF
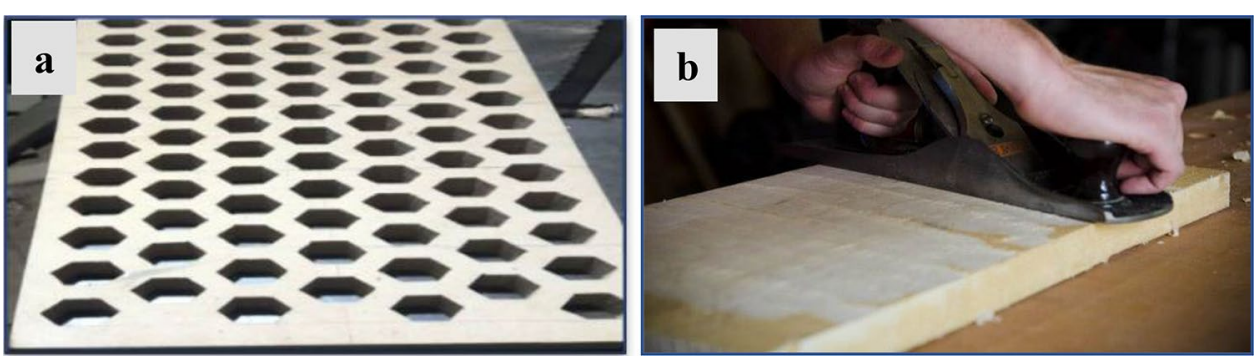

Fig. 3 Sandwich panels under load a three-point bending, $\mathbf{b}$ compression test
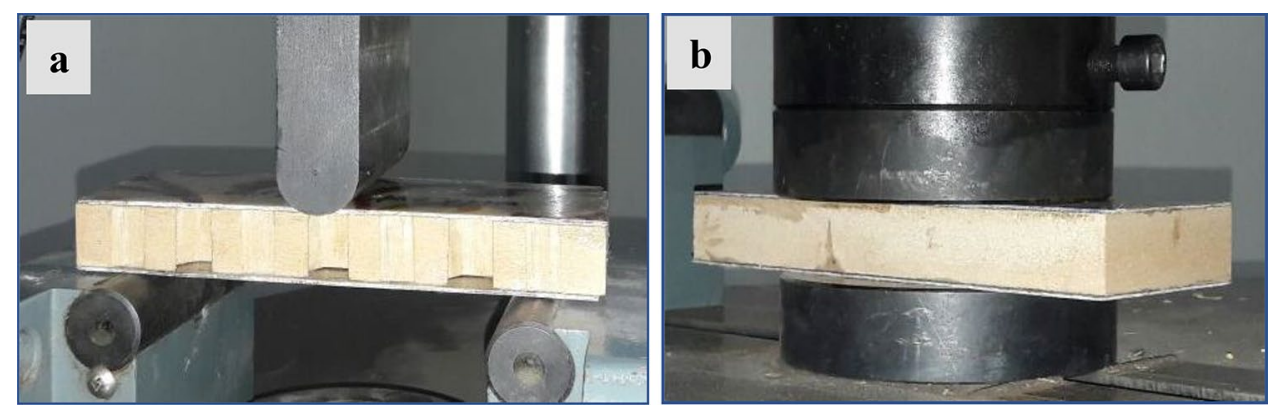
$\sigma_{b}=\frac{M\left[\frac{c}{2}+2\right]}{l}$

where $P_{\max }$ is a load to failure, $\mathrm{b}$ is panel width $(75 \mathrm{~mm}), \mathrm{c}$ is core thickness $(21 \mathrm{~mm}), \mathrm{d}$ is panel thickness $(25 \mathrm{~mm}), \mathrm{t}$ is face sheet thickness $(2 \mathrm{~mm}), \mathrm{S}$ is span length $(150 \mathrm{~mm})$ and $\mathrm{I}$ is a moment of inertia $\left(\frac{b d^{3}}{12}\right)$. Bending moment $(M)$ is equal to the product of load applied $\left(P_{\max }\right)$ and horizontal distance between rollers $(x=S / 2)$. In addition, the basic phenomena's of materials fabrication for multiple applications were also explained in the literature [24-31].

\section{Results and discussion}

\subsection{Bending tests}

\subsubsection{MDF honeycomb sandwich panels}

Load-displacement plots of MDF honeycomb sandwich panels with GFRP skin under three-point bending are

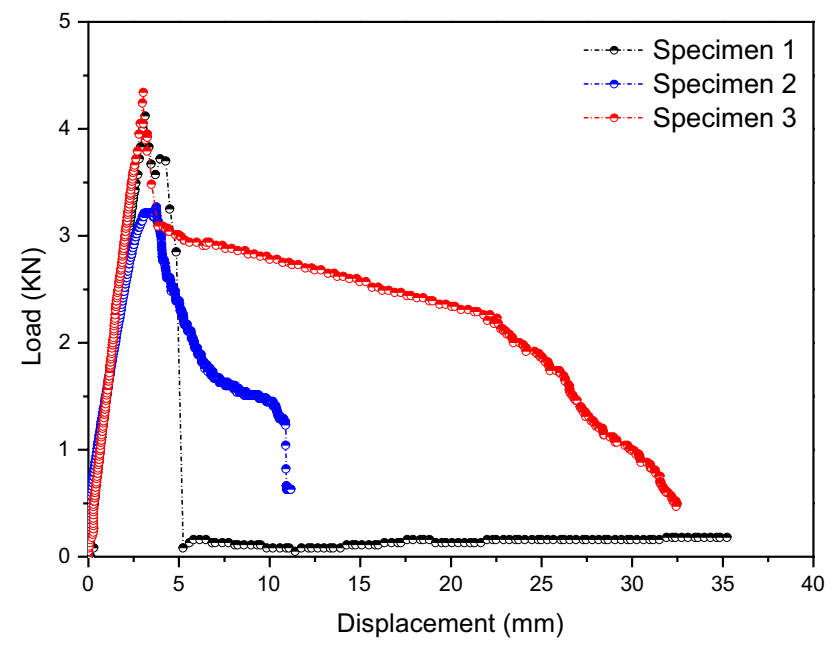

Fig. 4 Load-displacement response of MDF honeycomb sandwich panels in Fig. 4. When the load was applied on mid-span of the panel, a little deflection with increasing load was recorded due to the yielding of the panel. After the maximum load carrying ability of panel was achieved, the sudden drop in load was occurred due to the rapture of the core from the bottom of the panel. The core fracture was propagated in the transverse direction. The delamination at the upper and lower interface from end corners of panels was observed due to the complete bending of specimens. The variation in failure response is probably due to a very small difference in machining/manufacturing quality of panels. The failure mechanism is shown in Fig. 5. The average results in Table 2 show that sandwich panels with MDF honeycomb core have a lower load to failure, bending stress, core shear failure load and facing stress as compared to other specimens. However, the very large values of maximum deflection as compared to solid MDF sandwich panels indicate the gain in stabilization even after the failure. The advantage of such panels over solid MDF sandwich panels is the load carrying ability of panels after the failure due to the increase in the anisotropic nature of core.

\subsubsection{MDF honeycomb sandwich panels filled with wheat straw}

The load absorption capability of MDF honeycomb sandwich panels filled with wheat straw was increased due to the presence of wheat straw in empty regions of honeycombs. Such structures gain more stabilization as compared to the MDF honeycomb sandwich panels. Therefore, after the sudden drop in load, the load carrying ability of panels was higher as compared to other types of panels as shown in Fig. 6 . Moreover, the adhesion between core and face sheet was also increased due to the presence of wheat straw. The failure mechanism of such panels was the same as the failure behavior of MDF honeycomb sandwich panels.

\subsubsection{Solid MDF sandwich panels}

The load-displacement response in the case of solid MDF is shown in Fig. 7. The increase in load and displacement
Fig. 5 Failure behavior of MDF honeycomb sandwich panels a rapture of core from the bottom as well as delamination at the lower and upper interface from ends, b complete fracture of core in the transverse direction as well as the separation of facing from the right corner
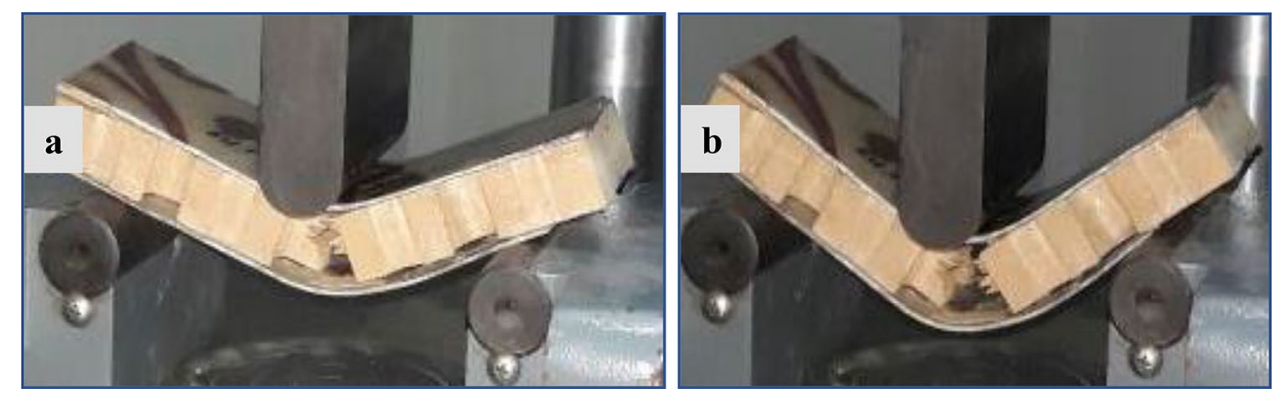
Table 2 Average value of three-point bending test results

\begin{tabular}{lcccc}
\hline Parameters & $\begin{array}{l}\text { MDF honeycomb } \\
\text { sandwich panel }\end{array}$ & $\begin{array}{l}\text { MDF Honeycomb sandwich } \\
\text { panel filled with wheat straw }\end{array}$ & $\begin{array}{l}\text { Solid MDF sand- } \\
\text { wich panel }\end{array}$ & $\begin{array}{l}\text { Sandwich panel } \\
\text { with plywood core }\end{array}$ \\
\hline Load to failure $(\mathrm{kN})$ & 3.91 & 4.37 & 6.09 & 11.16 \\
Standard deviation of failure load (kN) & 0.46 & 0.19 & 0.14 & 1.34 \\
Coefficient of variation of failure load (\%) & 11.78 & 4.33 & 2.28 & 12.03 \\
Deflection at failure (mm) & 3.31 & 3.26 & 3.59 & 3.05 \\
Maximum deflection (mm) & 26.30 & 28.63 & 3.59 & 11.17 \\
Core shear ultimate stress (MPa) & 1.13 & 1.27 & 66.19 & 3.23 \\
Maximum facing stress (MPa) & 42.50 & 47.50 & 41.95 & 121.30 \\
Maximum bending stress (MPa) & 13.30 & 41.95 & 107.14 &
\end{tabular}

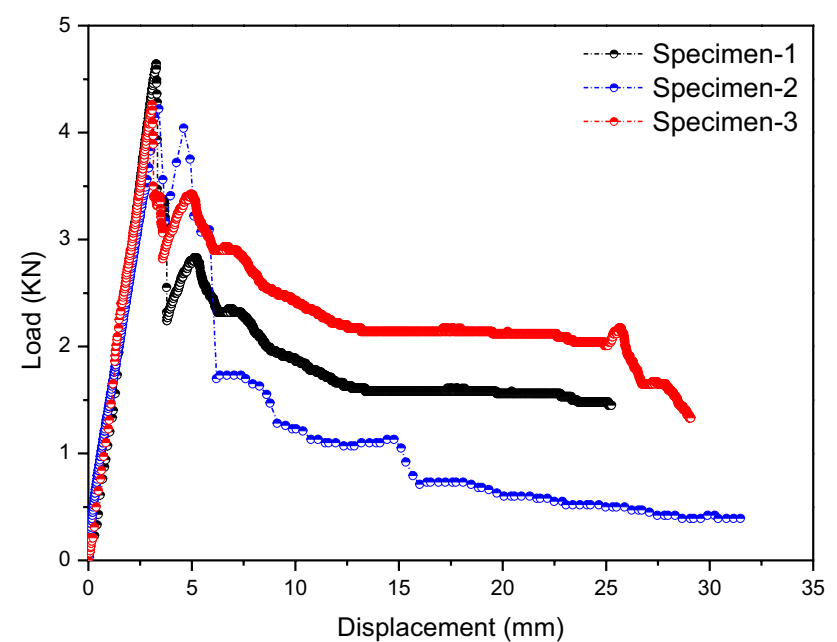

Fig. 6 Load-displacement response of MDF honeycomb sandwich panels filled with wheat straw

was approximately linear. After gaining maximum load, the panels were failed completely and there was no load carrying ability of panels after it. The failure was initiated due to debonding of face sheet at upper and lower interface and the core rapture from the bottom span bottom in the transverse direction was occurred as shown in Fig. 8a. Then the propagation in core fiber, as well as de-bonding at the upper and lower interface, was observed (c). A sample 1 showing maximum deflection was led to the core fracture in the longitudinal direction as shown in Fig. $8 \mathrm{~b}$.

\subsubsection{Sandwich panels with plywood cores}

The load-displacement response of sandwich panels with plywood core shows a non-linear behavior at higher displacements as shown in Fig. 9. Such panels have a higher load to failure and higher bending stress as compared to reference panels as presented in Table 2 . The continuous rise and fall of the load was indicated due to the orthotropic behavior of panels and GFRP facing resistance. The

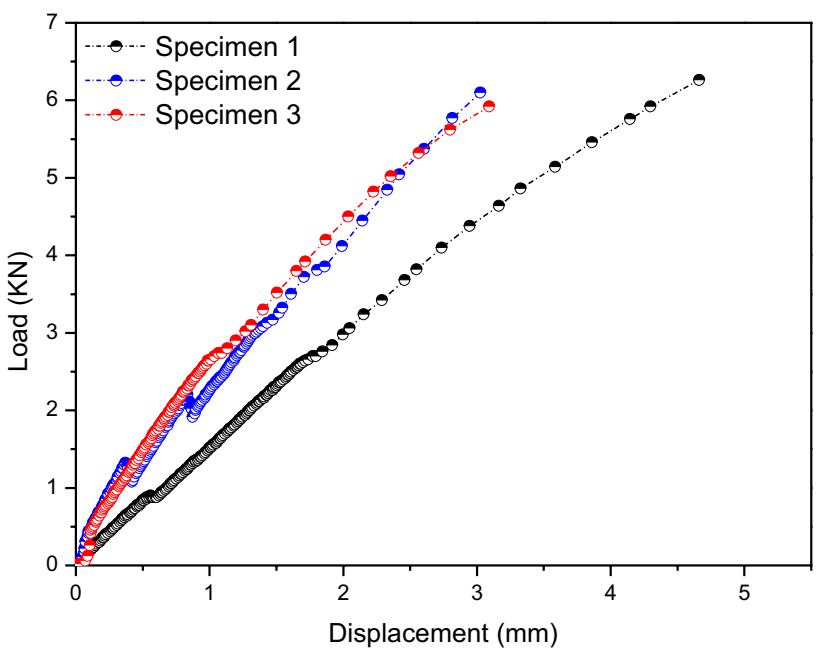

Fig. 7 Load-displacement response for solid MDF sandwich panels

failure of panels was occurred due to delamination of panels and fracture of panels from mid-span. The poor adhesion between core and face sheet was observed in such case as compared to all other reference materials.

\subsection{Compression tests}

The compression tests are useful for characterizing flat rectangular specimen that is meant to bear weight such as support beams in the building. The load-displacement behavior under compression tests is indicated in Fig. 10. The load-displacement response was almost linear. In case of solid MDF sandwich panels, the deviation in linear response was occurred at higher load as compared to MDF honeycomb sandwich panels. However, honeycomb sandwich panels finally fractured at higher loads as compared to sandwich panels with a solid core. This show that the honeycomb sandwich panels have the ability to carry high compressive loads as compared to sandwich panels with a solid core. This behavior was 
Fig. 8 Solid MDF sandwich panels under bending load a delamination of upper and lower face sheet and fracture of core from bottom in the transverse direction, $\mathbf{b}$ propagation of fracture in the longitudinal direction
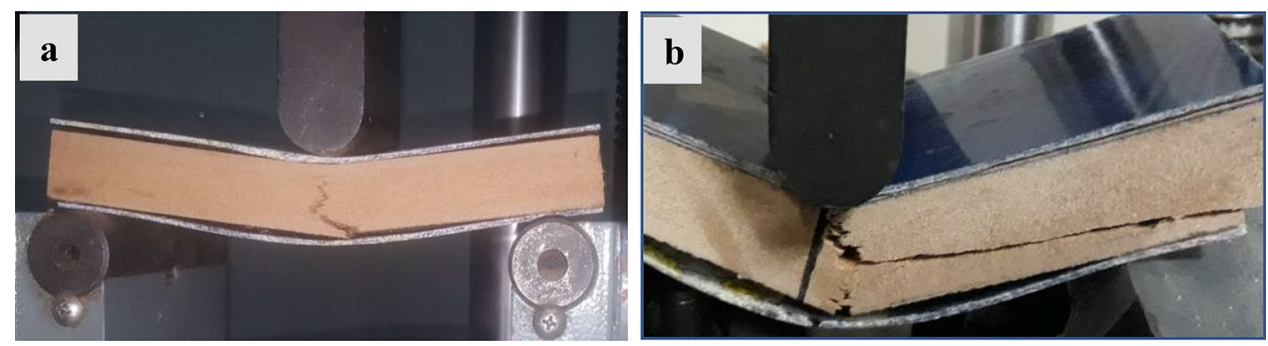

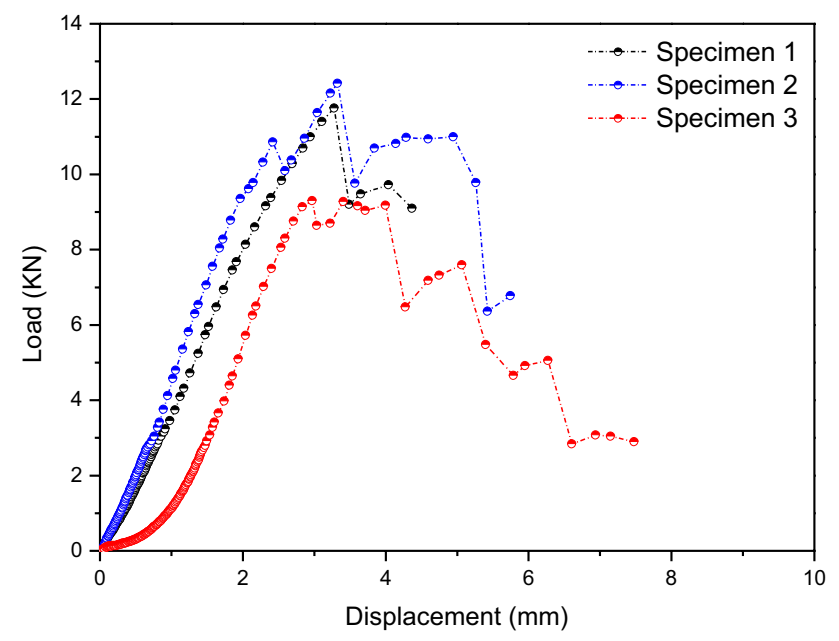

Fig. 9 The load-displacement response of sandwich panels with a plywood core

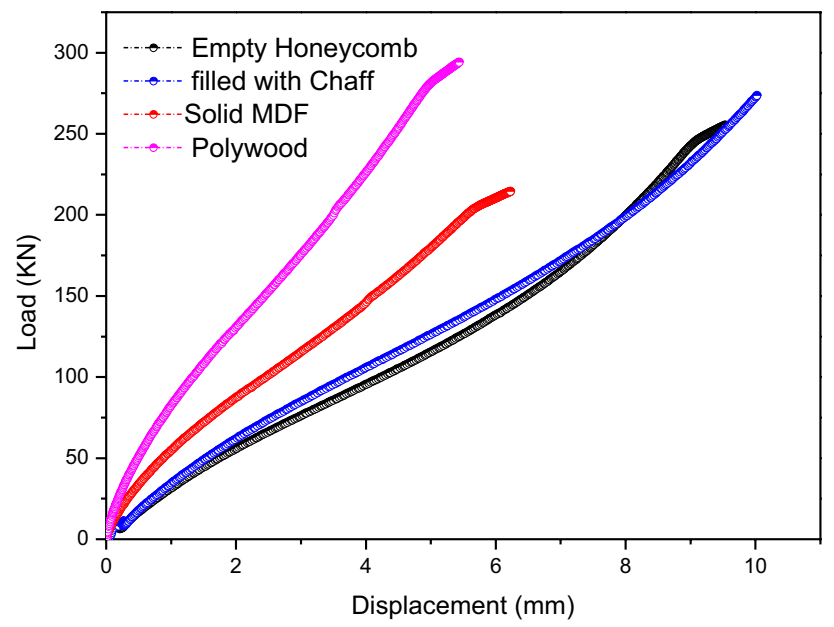

Fig. 10 Load displacement response under compression tests

probably due to the division of specimen in different sections. All the specimens were failed due to the core share failure. But in this case, the mechanism of core shear failure was different as compared to specimens under bending load. In bending the failure was occurred on mid-span and it was propagating in the transverse direction. While, in compression tests, the core shear was initiated from the ends of specimens and it was propagating toward mid of specimens as shown in Fig. 11.

\section{Conclusions}

The production and use of cement are one of the main cause of the emission of greenhouse gases. Moreover, the system used to provide heating and cooling services to a building increases the energy expenditures and climate temperature is expected to rise. Therefore, the objective of this work was to focus on the lightweight, sustainable and heat resistant prefab building construction materials. The wood-based sandwich panels were chosen to overcome such issues. The constituents of sandwich panels were selected on the bases of thermal characteristics, impact on climate and strength per weight. Due to ease in machining process medium density fiberboard (MDF) was selected. The MDF honeycomb core was developed to reduce the weight of the whole structure as well as consumption of wood elements. The hollow portions of honeycomb were filled with wheat straw to increase the heat resistance of the whole structure by maintaining the light weight of whole structures. The load-displacement response of sandwich structures under three points bending and compression loading was indicated for comparison of all type of structures. It was found that the load carrying ability of sandwich structures with solid MDF and plywood cores was higher as compared to sandwich structures with honeycomb cores. But the honeycomb sandwich panels have the ability to carry loads, even the load was applied after the failure. Load absorption capabilities of structures and strength were little improved by filling the structures with wheat straw. All the specimens were failed due to the rapture of core in transverse and longitudinal directions at mid span under bending load. While, in case of compression load, the specimens were failed due to the core shear failure in a transverse direction from the ends of specimens. The debonding at core and face sheet interface was found the significant problem, especially in case of solid wood-based sandwich panels and the inserts or bolts, are required to prevent the delamination. The

\section{SN Applied Sciences}



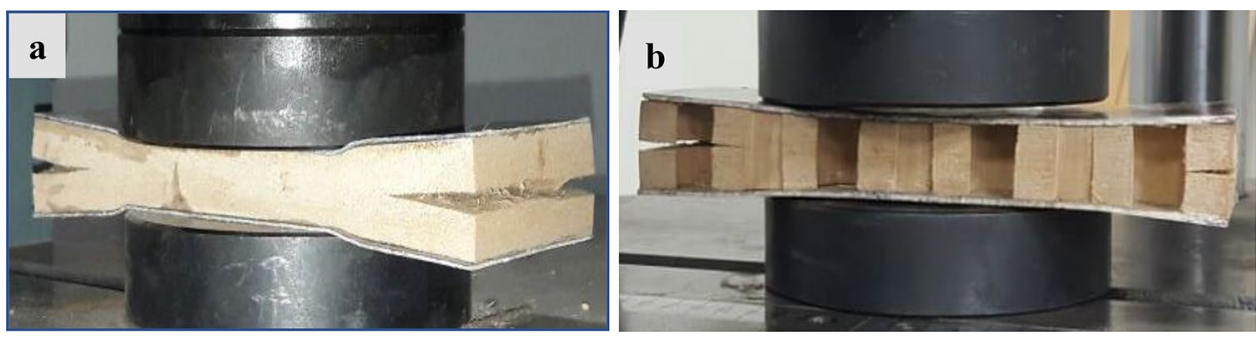

Fig. 11 Compression failure behavior of sandwich panels with solid and honeycomb cores a rapture of core from the ends of specimens in the transverse direction in case of solid MDF core, $\mathbf{b}$ rapture of core in the transverse direction in case of honeycomb structures

thermal and hygral performance of such panels needs to be investigated for making such panels suitable in tough environmental conditions.

Acknowledgements This research was jointly supported by Mechanical Engineering Department, NFC Institute of Engineering and Technology, Multan Pakistan under Faculty development program and School of Mechanical Engineering, Chung Ang University, Seoul, Republic of Korea.

\section{Compliance with ethical standards}

Conflicts of interest The authors declare no conflicts of interest.

\section{References}

1. Borsellino C, Calabrese L, Valenza A (2004) Experimental and numerical evaluation of sandwich composite structures. Compos Sci Technol 64:1709-1715

2. Krzyżak A, Mazur M, Gajewski M, Drozd K, Komorek A, Przybyłek $P$ (2016) Sandwich structured composites for aeronautics: methods of manufacturing affecting some mechanical properties. Int J Aerosp Eng 2016:1-10

3. Hussain M, Khan R, Badshah S, Abbas Z, ljaz M, Khan S (2017) Investigation of static and fatigue behavior of honeycomb sandwich structures under bending load. Tech J Univ Eng Technol (UET) Taxila Pak 22:72-80

4. Hussain M, Khan R, Abbas N (2019) Experimental and computational studies on honeycomb sandwich structures under static and fatigue bending load. J King Saud Univ Sci 31:222-229

5. Keller T, Rothe J, de Castro J, Osei-Antwi M (2014) GFRP-balsa sandwich bridge deck: concept, design, and experimental validation. J Compos Constr 18:04013043

6. Satasivam S, Bai Y (2016) Mechanical performance of modular FRP-steel composite beams for building construction. Mater Struct 49:4113-4129

7. Wimmers G (2017) Wood: a construction material for tall buildings. Nat Rev Mater 2:17051

8. Barbero E, Davalos J, Munipalle U (1994) Bond strength of FRPwood interface. J Reinf Plast Compos 13(9):835-854

9. Fotsing ER, Leclerc C, Sola M, Ross A, Ruiz E (2016) Mechanical properties of composite sandwich structures with core or face sheet discontinuities. Compos B Eng 88:229-239

10. Yan $L$, Kasal $B$, Huang $L$ (2016) A review of recent research on the use of cellulosic fibres, their fibre fabric reinforced cementitious, geo-polymer and polymer composites in civil engineering. Compos B Eng 92:94-132

11. Osei-Antwi M, de Castro J, Vassilopoulos AP, Keller T (2014) Structural limits of FRP-balsa sandwich decks in bridge construction. Compos B Eng 63:77-84

12. Farkas J, Jarmai K (1998) Minimum material cost design of fivelayer sandwich beams. Struct Optim 15:215-220

13. Chen Y, Ziehl PH, Harrison KW (2009) Experimental characterization and optimization of hybrid FRP/RC bridge superstructure system. J Bridge Eng 14:45-54

14. Ziehl PH, Engelhardt MD, Fowler TJ, Ulloa FV, Medlock RD, Schell E (2009) Design and field evaluation of hybrid FRP/ reinforced concrete superstructure system. J Bridge Eng 14:309-318

15. Zhou A, Tam L, Yu Z, Lau D (2015) Effect of moisture on the mechanical properties of CFRP-wood composite: an experimental and atomistic investigation. Compos B Eng 71:63-73

16. Jiang L, Walczyk D, Mclntyre G, Bucinell R, Tudryn G (2017) Manufacturing of biocomposite sandwich structures using mycelium-bound cores and preforms. J Manuf Process 28:50-59

17. Matalkah F et al (2017) Development of sandwich composites for building construction with locally available materials. Constr Build Mater 147:380-387

18. Jen Y-M, Chang L-Y (2008) Evaluating bending fatigue strength of aluminum honeycomb sandwich beams using local parameters. Int J Fatigue 30:1103-1114

19. Shen CJ, Lu G, Yu TX (2013) Dynamic behavior of graded honeycombs-a finite element study. Compos Struct 98:282-293

20. Yamashita M, Gotoh M (2005) Impact behavior of honeycomb structures with various cell specifications-numerical simulation and experiment. Int J Impact Eng 32:618-630

21. Ruan D, Lu G, Wang B, Yu T (2003) In-plane dynamic crushing of honeycombs - a finite element study. Int J Impact Eng 28:161-182

22. Zou Z, Reid SR, Tan PJ, Li S, Harrigan JJ (2009) Dynamic crushing of honeycombs and features of shock fronts. Int J Impact Eng 36:165-176

23. Boukharouba W, Bezazi A, Scarpa F (2014) Identification and prediction of cyclic fatigue behaviour in sandwich panels. Measurement 53:161-170

24. Naqi A, Abbas N, Zahra N, Hussain A, Shabbir SQ (2019) Effect of multi-walled carbon nanotubes (MWCNTs) on the strength development of cementitious materials. J Mater Res Technol 8(1):1203-1211

25. Benyounes A, Abbas N, Hammi M, Ziat Y, Slassi A, Zahra N (2018) Fabrication and characterization of novel transparent conducting oxide N-CNT doped $\mathrm{ZnO}$ for photovoltaic applications. Appl Phys A 124(2):90

26. Nawaz S, Awan MB, Saeed B, Abbas N (2019) Experimental investigation of taper angle during millisecond laser drilling of 
$18 \mathrm{CrNi8}$ steel under multiple parameters and defocused plane. Mater Res Express 6(8):086531

27. Sufyan $M$, Hussain $M$, Ahmad $H$, Abbas N, Ashraf J, Zahra N (2019) Bulge micro-textures influence on tribological performance of ultra-high-molecular-weight-polyethylene (UHMWPE) under phosphatidylcholine (Lipid) and bovine serum albumin (BSA) solutions. Biomed Phys Eng Express 5(3):035021

28. Ziat Y, Abbas N, Hammi M, Echihi S (2019) An experimental evaluation of inhibiting corrosion effect of phosphate glass on mild steel in acidic solution. Mater Res Express 6(8):086567

29. Zahra N, Abbas A, Saeed B, Abbas N, Hussain M (2018) Synthesis and characterization of $\mathrm{Nd}$-substituted lithium nickel nano ferrites using co-precipitation method. Nanosci Nanotechnol Lett 10(8):1142-1146
30. Raza K, Khan TA, Abbas N (2018) Kinematic analysis and geometrical improvement of an industrial robotic arm. J King Saud Univ Eng Sci 30(3):218-223

31. Naqi A, Abbas N (2017) Experimental investigation on the contribution of pristine multi-walled carbon nanotubes (MWCNTs) addition to the strength enhancement of cement composites. In: IEEE 3rd international conference on engineering technologies and social sciences (ICETSS), pp 1-3

Publisher's Note Springer Nature remains neutral with regard to jurisdictional claims in published maps and institutional affiliations. 